\title{
Effects of Factors Influencing Residential Property Negotiation Process on Market Outcome in Akure, Nigeria
}

\author{
OLADAPO, Rasidat Adejoke Ph.D. \\ Department of Estate Management, Federal University of Technology, Akure Nigeria
}

\begin{abstract}
This study determined the effect of factors influencing residential property negotiation process on the final market outcome in Akure, Nigeria. The research design was field survey in which the target population were the property buyers within the three selected residential densities of the city. Data was elicited from the self administered structured questionnaire to the 400 property buyers sampled. Data analysis was performed using logistic regression model where the dependent variable was market outcome and the independent variables were eleven dichotomous variables. The findings revealed that some variables showed significant values at $p$-value $\geq 0.05$ influences on market outcome. These variables were agents' commission, owners' reservation prices, communication channel, property titled, duration of transaction, owners' negotiators behaviours and neighbourhood characteristics. The variables that showed insignificant values of influence on market outcome were number of negotiators in each transaction, buyers' reservation price, strategy employed, buyers' negotiation behaviour; and cultural differences. There was information asymmetry between the owners' negotiators and buyers as most of the buyers did not have an independent negotiators to strike a fair outcome (final price) The study therefore recommended two independent and skilled negotiators who had the detailed knowledge of information on the previous market condition and range upon which to strike a fair deal. Equally there should be parallel market price regulatory agencies that must keep and regularly display past records of transactions. Such must be used to negotiate present transactions. No doubt this will break the information advantage that often make owners to have an edge over the buyers.
\end{abstract}

Keywords: Akure, Market Outcome, Negotiation Process, Property, Residential

DOI: $10.7176 / \mathrm{JESD} / 12-8-08$

Publication date: April $30^{\text {th }} 2021$

\section{INTRODUCTION}

Real property negotiations usually serve as means to settle buyer and seller interaction concerning final price, date of delivery, and service contracts (Sabine, Markus and Uta, 2009). The market is positioned in such a manner that sellers normally have in mind a particular price (reservation prices) below which the deal may not be successful; and the buyers want to pay less based on their reservation prices above which there may not be transaction.. To purchase the real property at a fair price, negotiation must take place. Such fair price should involve well informed negotiators or agents for both parties in order to strike fair deal. In practice especially in the environment where most of the market participants are not well informed about the operations of the market, the ideal things do not mostly prevail in most transactions. This situation leads to economic imbalance in which real property market characteristics actually exhibit. Due to relative fixity of the property, the property owners /sellers often have information advantages over the buyers. Hence, most property owners dictate prices or asking prices which may be the final price or market outcome. Ack and Diaz (1996) argue that due to limited human information processing capacity, potential homebuyers often use the asking value on a home as a shortcut to arrive at negotiated / final value. Most often, asking price or value is the ceiling price for the negotiations between sellers and buyers on seller's side, while negotiated value represent negotiators' price targets as the best settlement between both parties. (Zetik \& Stuhlmacher, 2002). Then, this depends on both negotiators' (seller and buyer) skill and experience within the market.

Market negotiation process requires quality representation of parties' interests, sharing enough information, parties being in equal information power, negotiators whose motives, talent, and aspirations are not conflicting. In practice or reality, some of these processes that could lead to fair outcome are absent. Muhlebach (2005) viewed that the outcome in the property market are set on an individual transaction basis and usually ends up in an agreement that is preconceived by conflicting negotiators or parties. Thus an ill conceived negotiation process will cause most of the sub-optimal outcome experienced in property market transaction. Where the influence of one party on the asking price creates threat to the other party cannot allow mutual beneficial outcome to prevail. Most property market outcome ends up in unequal bargaining in favour of owners more than the other party. This is not a rational situation for real property as an economic good.

The real property market operations have come of age within Akure city development. The city was once an administrative one in 1976 when Ondo State was carved out of the Western Region of Nigeria, with its capital seat at Akure has been advancing and growing both in population and land use development. The city actually enjoys a fairly flat physical and topographic terrain that have encouraged sporadic residential land use development. Other features of interest are its commercial and industrial property developments which have been on the increase. 
All these have necessitated establishments of professionals / service providers among whom the property managers/agents have been triumphing.

However, within the Akure property market, there are no official or written institutional arrangement on transactions. Although there are professional properties managers being referred to as Estate Surveyors and Valuers that often handled the sales or letting of their clients' real property. Their role in the market is not forced on any property owners or users. It all depends upon their desire to employ them for their professional services., while, some property owners handled their marketing and management of their real property by themselves.. So most of those property transaction, brokering, marketing and closing are handled by the property owners who do not keep any records or report their property activity with any authority or institution for record keeping or as information databank. In sales or letting arrangement, there are no information or records about past transactions within the market. So there is limited human information processing capacity among potential buyers. Most initial or asking price/ value from the property owners are often the final price. This situation suggest that there are no negotiation process in most deals, Final price ought to represents negotiated price targets from a buyers side, depending upon buyers' skill. In practice, hardly can one observe a quality representative of all parties to negotiations because of lack of enough information on past transaction and lack of present information to facilitate greater success in negotiation.

The institutional arrangement to co-ordinate the market transaction is therefore very weak. it lacks administration and monitoring of sales volume either from professional context, public agencies or other spiritfitted information providers. Yet, over the past two(2)-four(4) decades now, the volume of land transaction especially on private land in Akure city has been enormous. This has led to spontaneous expansion of land use in all the urban fringe areas of the city. There is therefore, need to investigate the market negotiation process that lead to most residential property transaction outcome in the Akure property market. The remaining aspect of the paper contains review of related works, research methods, discussion of results conclusion and recommendations.

\subsection{LITERATURE REVIEW}

Several studies have been carried out on market negotiation power, asking price, effect of agents on negotiation outcomes, real property marketing, time on market, factors influencing real estate property prices, anchor, reference and adjustment on price of commodities in United Kingdom, United States of America ( Bazeman, Curhan, More \& Valley., 2000, Black and Diaz, 1996, Fatima, Wooldridge and Jennings, 2001; Wilhelmsson, 2008, Messah and Kigige, 2011, Gatzlaff and Liu, 2013, and little has been done in respect of property market negotiation process and outcome in Nigeria (Iroham et al, 2011a)

For instance, Bazerman et al (2000) studied the effect of agents and mediators on negotiation outcomes, using multiple regression analysis, the study explored the influence of agents and alternative third-party termed mediators roles on negotiated outcomes and the likelihood of impasse/settlement. Findings revealed that the selling price of property is higher when an agent is used (because of agent's commission) than when no intermediary is involved This arrangement still depend upon who the agent acted for. When the agent acts for the property owner, the potential buyer is often left in their whims and caprices. The ideal would have being that both parties have their separate agents to ensure fair outcome. The study was carried out in United Kingdom and the extent to which professional estate agents or other third party are involved in negotiation in Akure, Nigeria need to be studied.

Black and Diaz (1996) research on the use of information on asking price in the property negotiation process, using experimental method. The study revealed that there were manipulation on final price as buyers' opening offer and eventual settlement price were based on buyers pre knowledge of the asking price. The basis of negotiation would have been prevailing market range instead of asking prices with no recourse to market value of comparable properties. Fatima, et al, (2001) investigation on optimal negotiation strategies for agents with incomplete information, analyzed the process of automated negotiation between two competitive agents that have firm deadlines and incomplete information about their opponent. The study developed a negotiation model based on factors of influence on outcome. It concluded that the outcome of a negotiation depends on many parameters which include the agents' preferences, owners' reservation limits, their attitude toward time and the strategies they employed. In an attempt to obtain the best price, agents usually ensure that negotiation ends before a certain deadline.; thus suggesting that duration of transaction influences negotiation outcome.

This study intends to beef-up these variables of influence by adding communication channel, agent commission and others as part of the factors which can influence negotiation outcome.. For instance, owner/principal' influence was found to impact upon market outcomes in valuation brief (Amidu and Aluko, 2007). Although in most cases it is possible for agents to have complete information about all these parameters against its opponent. Wilhelmsson (2008) examined evidence of buyer bargaining power in the Stockholm residential estate market. This study investigated whether uninformed buyers pay higher prices for single-family houses than informed buyers; and tests whether the bargaining power increases with information. Data on real estate prices and attributes were examined, as well as household characteristics and buying process. The results revealed that uninformed buyers pay higher prices than informed buyers and bargaining power was not found to 
be weak for a first-time buyer but it was weaker if the household had participated in several biddings and lost.

This study intends to determine the extent to which bargaining process prevail in most outcome.

Iroham, Oluwunmi and Oluwatobi (2011a) exposition on Principals' Influence in Real Estate Negotiation entailed a survey of 159 Estate Surveyors and Valuers in Lagos metropolis, Nigeria. It was found that potential tenants were prompt in influencing real estate negotiation through the use of reward powers and information power as pecuniary gains are offered to the Estate Surveyors and Valuers (Agents) in order to accomplish their whims. Access to information by the principals is also used against the Estate Surveyor and Valuers working in an unfamiliar terrain. From the two findings in the study, it means both parties' behaviours influences transaction outcome.

Gatzlaff and Liu (2012) examined list price information in the negotiation of commercial real estate transactions, Using a two-stage selection correction model, the study showed that office properties which provide list (asking) price information are (on average) associated with lower price outcomes signifying that both parties are well informed about negotiation outcome. The study focused on commercial property and the extent to which negotiation prevails in residential properties transactions is desirable.

Dirk, Moosmayer, Alain, Martin and Bjoern (2013) used neural network approach in predicting price negotiation outcomes in business to business context and compare the result with regression analysis and the result reveals that target price played a more important role in price negotiation. The study was based on the influence of target price on negotiation of fungible commodity which is different from the heterogeneous nature of real property transaction. Target price can be likened to asking price but ought not to be arbitrarily fixed or monopolised.

Leigh and Khakhar (2015) assessed the effect of negotiator characteristics on the success of international B2B negotiations through the online survey of international business executives working in the UK on the success of their most recent negotiating experience in terms of integrative and distributive outcomes. Employing chi-square statistical analysis showed that the respondents' individual motivation appears to have a negative effect on integrative outcomes while, as expected, the other characteristics had a positive effect. The study was carried out on business services / commodity and not on real estate transactions.

Furthermore, conventional wisdom has long maintained that some people are good negotiators and others are not (Thompson 2005). Here, the successful negotiation can be attributed primarily to natural skill or talent. Neil and Kevin (1995) argued from this standpoint that, a good negotiator is a very skilful communicator, a person who has developed their interpersonal skills to the point where reflective listening, assertion, interest-base questioning, and facilitation are their second nature. Swaidan (2007) also pointed out that cultural factor and language differences influence the negotiations process among parties

In conclusion, this study considered the influence of those factors that have been established from literature (agents commission, owners and buyers reservation prices, communication skill; channel strategy employed, owners' and buyers' negotiators behaviour, cultural differences, duration of transaction, property titled and neighbourhood characteristics) as the factors influencing negotiation process on the market outcome. Its findings would be of immense benefit to potential buyers and tenants in real property transactions and the possibility of employing the services of skilled negotiators (Estate Surveyors and Valuers) in order to achieve fair outcome in property transaction..

\subsection{MATERIALS AND METHODS}

The study was a field survey research which target population were the prospective land/property buyers in the three residential densities selected for the study. The sample size of buyers within the three areas were 400. The property buyers negotiators' details were obtained from the revenue department of the Board of Internal Revenue of the State Stratified and systematic random sampling were adopted to group the residential areas into low, medium and high zones to elicit information from land/property buyers.. Structured questionnaire was later designed to collect relevant data from the buyers for the analysis. The method of analysis employed inferential statistic of Logistic regression to analyze the effect of the factors that influence negotiation process on the market outcome in the study area. The nominal variable is the dependent variable while the measurement variable is the independent variable and it takes the form of the equation below:

$\operatorname{Logit}(p)=b_{0}+b_{1} X_{1}+b_{2} X_{2}+b_{3} X_{3}+b_{4} X_{4}+\ldots \ldots \ldots \ldots \ldots .+b_{n} X_{n}$

Where $\mathrm{p}=$ dependent variable $; \mathrm{b}_{0}=$ constant; $\mathrm{b}_{1}, \mathrm{~b}_{2}, \mathrm{~b}_{3}, \ldots \ldots . . \mathrm{b}_{\mathrm{n}}=$ regression coefficient

$\mathrm{X}_{1}, \mathrm{X}_{2}, \mathrm{X}_{3}, \ldots \ldots . . \mathrm{X}_{\mathrm{n}}=$ independent variables; and $\mathrm{n}=$ number of predicted variables

For this study, multiple/ logistic regression was used to analyse the effects of the factors that influence negotiation outcomes of most property transactions in the study area. The dependent variable was the market outcome which took the form of categorical data of fairness or otherwise(unfairness). There were twelve independent variables in which their measurement scales were dichotomous in order to avoid multi - co linearity problem among them. These were number of negotiators, agent/negotiators commission, seller and buyers reservation price, communication channel between parties or their negotiators, strategy employed, sellers' and buyers' negotiators behaviours, parties cultural differences duration of transactions, property titled and 
neighbourhood characteristics with their scale of measurement in table 1 below.

Table1: Specification and Definition of Variables Used

\begin{tabular}{|c|c|c|}
\hline Variable Code & Definition of Variables & Measurement Scale \\
\hline NEGOUT & $\begin{array}{l}\text { Dependent Variable: } \\
\text { Negotiation Outcome }\end{array}$ & $1=$ Fair Outcome; $0=$ Otherwise \\
\hline \multicolumn{3}{|c|}{ Independent Variables: } \\
\hline NUNEGO & $\begin{array}{l}\text { Number of Negotiator in } \\
\text { Transactions }\end{array}$ & $\begin{array}{l}1=\text { Seller negotiator only } \\
0=\text { Both Parties have negotiators }\end{array}$ \\
\hline AGENCO & Agents Commissions seller/ buyer & Actual \% \\
\hline SEREPRI & Seller Reservation Price & $\begin{array}{l}1=\text { Higher than Market range } \\
0=\text { Deadlock }\end{array}$ \\
\hline BUREPRI & Buyer Reservation Price & $\begin{array}{l}\text { 1- same as asking price } \\
0=\text { Lower than Asking Price }\end{array}$ \\
\hline $\mathrm{COMMCH}$ & Communication Channel between Parties & $\begin{array}{l}1=\text { Face-to-face } \\
0=\text { other means }\end{array}$ \\
\hline STRATEM & Strategy Employed & $\begin{array}{l}1=\text { Listening and Sharing Information } \\
0=\text { otherwise }\end{array}$ \\
\hline OWNEGOB & Owner' Negotiator Behaviour & $\begin{array}{l}1=\text { Increase in Market range } \\
0=\text { No Increase }\end{array}$ \\
\hline BUYNEGOB & Buyer Negotiator Behaviour & $\begin{array}{l}1=\text { Decrease in Asking Price } \\
0=\text { No decrease }\end{array}$ \\
\hline PCULTD & Parties' Cultural Differences & $\begin{array}{l}1=\text { Same Culture } \\
0=\text { Different Culture }\end{array}$ \\
\hline DURATR & Duration of Transaction & Actual Month \\
\hline PTITLED & Property Titled & $1=$ Available $.0=$ otherwise \\
\hline NEIGHBCH & Neighbourhood Characteristics & $1=$ serene one, $0=$ otherwise \\
\hline
\end{tabular}

\subsection{FINDINGS AND DISCUSSION OF RESULTS}

In this section, data collected for the analysis were obtained through the structured questionnaire administered to the 400 property buyers within the three selected residential densities, out of which 369 were retrieved representing 92 percent response rate being used for the analysis needed.

Table 2: Socio-Economic Background of the Buyers/Occupants in the Three Residential Densities in Akure

\begin{tabular}{lcccccc}
\hline $\begin{array}{l}\text { Socio-Economic Background of the } \\
\text { Property Buyers/Occupants }\end{array}$ & \multicolumn{2}{c}{ High Density } & \multicolumn{2}{c}{ Medium Density } & \multicolumn{2}{c}{ Low Density } \\
\cline { 2 - 7 } & Frequency & Percent & Frequency & Percent & Frequency & Percent \\
\hline Respondents Age & 8 & 4.9 & 6 & 5.4 & 6 & 6.4 \\
Below 30 Years & 43 & 26.4 & 27 & 24.1 & 26 & 27.7 \\
31 - 40 Years & 56 & 34.4 & 37 & 33.0 & 34 & 36.2 \\
41 - 50 Years & 40 & 24.5 & 30 & 26.8 & 20 & 21.3 \\
51 - 60 Years & 16 & 9.8 & 12 & 10.7 & 8 & 8.5 \\
61 Years and above & $\mathbf{1 6 3}$ & $\mathbf{1 0 0 . 0}$ & $\mathbf{1 1 2}$ & $\mathbf{1 0 0 . 0}$ & $\mathbf{9 4}$ & $\mathbf{1 0 0 . 0}$ \\
Total & & & & & & \\
Gender & 121 & 74.2 & 85 & 75.9 & 70 & 74.5 \\
Male & 42 & 25.8 & 27 & 24.1 & 24 & 25.5 \\
Female & $\mathbf{1 6 3}$ & $\mathbf{1 0 0 . 0}$ & $\mathbf{1 1 2}$ & $\mathbf{1 0 0 . 0}$ & $\mathbf{9 4}$ & $\mathbf{1 0 0 . 0}$ \\
Total & & & & & & \\
Educational Qualification & 27 & 16.6 & 15 & 13.4 & 18 & 19.1 \\
OND & 40 & 24.5 & 24 & 21.4 & 28 & 29.8 \\
HND & 48 & 29.4 & 37 & 33.0 & 24 & 25.5 \\
B. Sc & 32 & 19.6 & 24 & 21.4 & 16 & 17.0 \\
M. Sc & 16 & 9.8 & 12 & 10.7 & 8 & 8.5 \\
PhD & $\mathbf{1 6 3}$ & $\mathbf{1 0 0 . 0}$ & $\mathbf{1 1 2}$ & $\mathbf{1 0 0 . 0}$ & $\mathbf{9 4}$ & $\mathbf{1 0 0 . 0}$ \\
Total & & & &
\end{tabular}




\begin{tabular}{|c|c|c|c|c|c|c|}
\hline \multirow{2}{*}{$\begin{array}{l}\text { Socio-Economic Background of the } \\
\text { Property Buyers/Occupants }\end{array}$} & \multicolumn{2}{|c|}{ High Density } & \multicolumn{2}{|c|}{ Medium Density } & \multicolumn{2}{|c|}{ Low Density } \\
\hline & Frequency & Percent & Frequency & Percent & Frequency & Percent \\
\hline \multicolumn{7}{|l|}{ Occupation } \\
\hline Civil Servants & 48 & 29.4 & 35 & 31.3 & 24 & 25.5 \\
\hline Self-Employed & 32 & 19.6 & 24 & 21.4 & 16 & 17.0 \\
\hline Private Company & 74 & 45.4 & 48 & 42.9 & 48 & 51.1 \\
\hline Retired Person & 9 & 5.5 & 5 & 4.5 & 6 & 6.4 \\
\hline Total & 163 & 100.0 & 112 & 100.0 & 94 & 100.0 \\
\hline \multicolumn{7}{|l|}{ Marital Status } \\
\hline Single & 18 & 11.0 & 10 & 8.9 & 12 & 12.8 \\
\hline Married & 113 & 69.3 & 78 & 69.6 & 66 & 70.2 \\
\hline Divorced & 24 & 14.7 & 18 & 16.1 & 12 & 12.8 \\
\hline Widow & 8 & 4.9 & 6 & 5.4 & 4 & 4.3 \\
\hline Total & 163 & 100.0 & 112 & 100.0 & 94 & 100.0 \\
\hline \multicolumn{7}{|l|}{ Monthly Income } \\
\hline Less than $\# 30,000$ & 9 & 5.5 & 5 & 4.5 & 3 & 3.2 \\
\hline$\# 30,001$ - \#50,000 & 12 & $7 . .3$ & 7 & 6.3 & 6 & 6.4 \\
\hline$\# 50,001$ - \#70,000 & 56 & 34.4 & 36 & 32.1 & 32 & 34.0 \\
\hline$\# 70,001$ - \#90,000 & 56 & 34.4 & 44 & 39.3 & 28 & 29.8 \\
\hline Above $\# 90,000$ & 30 & 18.4 & 20 & 17.8 & 25 & 26.6 \\
\hline Total & 163 & 100.0 & 112 & 100.0 & 94 & 100.0 \\
\hline \multicolumn{7}{|l|}{ Plot Size } \\
\hline $15 \mathrm{~m} \times 30 \mathrm{~m}$ & 131 & 80.4 & 88 & 78.6 & 78 & 83.0 \\
\hline $18 \mathrm{~m} \times 36 \mathrm{~m}$ & 16 & 9.8 & 14 & 12.5 & 8 & 8.5 \\
\hline $36 \mathrm{~m} \times 72 \mathrm{~m}$ & 8 & 4.9 & 5 & 4.5 & 4 & 4.3 \\
\hline $30 \mathrm{~m} \times 30 \mathrm{~m}$ & 8 & 4.9 & 5 & 4.5 & 4 & 4.3 \\
\hline Total & 163 & 100.0 & 112 & 100.0 & 94 & 100.0 \\
\hline
\end{tabular}

Table 2 described the socio-economic background of the property buyers/ occupants of the high density, medium and low density residential areas within Akure city. Various characteristics such as the age, gender, educational qualification, occupation, marital status, monthly income amongst other were shown to justify the reliability of the data needed for subsequent analysis in this study.

The descriptive statistics in table 2, revealed that majority of the buyers across the three densities are within the age bracket of $41-50$ years representing $34.4 \%, 33 \%$ and $36.2 \%$ t respectively. This was closely followed by the buyers within the age bracket of 31-40 years representing $26.4 \%, 24.1 \%$ and $27.7 \%$ in the high, medium and low density areas. The age distribution of the buyers thus showed that they were advanced in age. Therefore, their opinion relating to the effect of the negotiation process on market outcome should be adequate.

The gender distribution was mostly male representing $74.2 \%, 75.9 \%$ and $74.5 \%$ among the property buyers in the high, medium and low density areas. These percentages showed higher number of male than female buyers in the selected areas in Akure. Their gender distributions relative to their educational qualification revealed that most of the buyers in the high and medium density areas are learned with B.Sc holders representing highest percents of $29.4 \%$ and $33 \%$ respectively. The buyers/occupants within the low density areas were mostly HND holders representing $29.8 \%$. than the HND holders in the high and medium density areas $(24.5 \%$ and $21.4 \%)$. The educational qualification of the respondents as shown in table 2 above showed that the buyers sampled were well educated and their opinion the subject matter would be accurate.

The data on buyers' occupation also revealed that most of the respondents were working in private establishment/ companies representing $45.4 \%, 42.9 \%$ and $51.1 \%$ within the three areas (high, medium and low density) respectively. The civil servants represents $29.4 \%, 31.3 \%$ and $25.5 \%$ respectively while the self-employed represents $19.6 \%, 21.4 \%$ and $17.0 \%$ as opined by the occupants in the high, medium and low density areas. The marital status of the respondents revealed that most of the buyers are married representing $69.3 \%, 69.6 \%$ and $70.2 \%$ in the high, medium and low density areas. The findings of the occupation and marital status further implied that these buyers were matured enough to understand the essence for the study.

The data on the monthly income of the buyers also showed that most of them in the three areas received minimum of $\# 50,000$ and above representing $87.2 \%, 89.2 \%$ and $80.4 \%$ respectively. These showed that their economic status should be able to influence their decisions From the perspectives of the occupants in the medium densities, majority of respondents collect \#70,000 and above representing 39.3\% and those within \#50,001 $\# 70,000$ represents $32.1 \%$. The plot size of the property mostly purchased by the buyers within the three densities was $15 \mathrm{~m} \times 30 \mathrm{~m}$ representing $80.4 \%, 78.6 \%$ and $83.0 \%$ within the high, medium and low density areas respectively. This implied the preference for that plot size among the layout in the areas. 


\subsection{EFFECT OF NEGOTIATION PROCESS ON THE MARKET OUTCOME}

\subsection{Logistic Model Fitness Tests}

Binary logistic regression was explored to assess the effect of the factors that influence negotiation outcome in the study area. Before the model, the adequacy of LRM is evaluated by considering the overall model evaluation, statistical test of each predictor, goodness-of-fit test and validation of predicted probability. The result of the analysis in tables 2,3 and 4 are discussed to ascertain the adequacy and reliability of the LRM is presented below. Table 2: Omnibus Tests of Model Coefficients

\begin{tabular}{llccc}
\hline & & Chi-square & Df & Sig. \\
\hline \multirow{3}{*}{ Step 1 } & Step & 124.194 & 12 & .000 \\
& Block & 124.194 & 12 & .000 \\
& Model & 124.194 & 12 & .000 \\
\hline
\end{tabular}

Table 2 gives us an overall indication of how well the model performs over and above the results obtained for classification table (when no predictor variables was entered into the model) which is referred to as a "goodness of fit" test. This set of result shows the goodness of fit and the adequacy of the predictors in the model by having a lower chi-square of 124.194 and a highly significant value which is less than 0.05 . Hence, the result from Table 16 shows a significance of 0.000 which means that the value of $p<0.005$. Thus, the model with the set of variables used as predictors is adequate; and that all the predictors have influence on the negotiation outcome

Table 3: Classification Table ${ }^{\text {a }}$

\begin{tabular}{|c|c|c|c|c|c|}
\hline & \multirow[t]{3}{*}{ Observed } & & \multicolumn{3}{|c|}{ Predicted } \\
\hline & & & \multicolumn{2}{|c|}{ Negotiation Outcome } & \multirow{2}{*}{$\begin{array}{c}\text { Percentage } \\
\text { Correct }\end{array}$} \\
\hline & & & Unfair & Fair & \\
\hline \multirow{3}{*}{ Step 1} & \multirow{2}{*}{ Negotiation Outcome } & Unfair & 22 & 25 & 46.8 \\
\hline & & Fair & 5 & 317 & 98.4 \\
\hline & \multicolumn{2}{|l|}{ Overall Percentage } & & & 91.9 \\
\hline
\end{tabular}

a. The cut value is .500

Table 3 provides an indication of how well the model is able to predict the correct category (unfair/fair outcome). The overall percentage 91.9 falls within the recommended standard of a good model which is between 71 percent and 95 percent (FOQ, 2012)

Table 4: Hosmer and Lemeshow Test

\begin{tabular}{lccc}
\hline Step & Chi-square & Df & Sig. \\
\hline 1 & 2.162 & 8 & .976 \\
\hline
\end{tabular}

Table 4 shows the goodness of fit which statistics which asserts the fit of a LRM against actual outcome. The Homer and Lemeshow is used to test whether there is no relationship between the predictors variables and the log odds of the response variable. Peng et.al (2002) asserts that when this test is not significant, then it suggests that the nodel fits the data well. In the table 4 , the chi square statistics figure is $2.162(\mathrm{p}=0.976)$ which is nor significant . This implies that there is relationship between the weighted combination of the predicted variables and the log odds of the criterion variable.

Table 5: Summary Variation on Cox \& Snell R-Square and Nagelkerke R-Square

\begin{tabular}{lccc}
\hline Step & $\mathbf{- 2}$ Log likelihood & Cox \& Snell R Square & Nagelkerke R Square \\
\hline 1 & $157.249^{\mathrm{a}}$ & .286 & .536 \\
\hline
\end{tabular}

a. Estimation terminated at iteration number 7 because parameter estimates changed by less than .001 .

Table 5 reveals the Cox and Snell R Square and the Nagelkerke R Square values which provide an indication of the amount of variation in the dependent variable explained by the model (from a minimum value of 0 to a maximum value of approximately 1 ). The two values 0.287 and 0.536 , suggest that the model is adequate as not much variation is observed between the two values and the factors explain between $28.7 \%$ and $53.6 \%$ of the variability in the factors influencing negotiation outcome.

\subsection{Variables of Influence on Negotiation Outcome in the equation}

Table 6 showed the logit regression result with coefficient (B) of independent variables, significant (sig) odd ratio (Exp B) of each of the independent variables.. The findings revealed the variables/factors that influenced market outcome. In the significant column, values less than 0.05 are variables that contribute significantly to the predictive ability of the model, they are significant at $\mathrm{p}$ value $\leq 0.01$ and, 0.05 while values greater than 0.05 were variables that do not contribute significantly to the predictive ability of the model. 
Table 6: Variables in the Equation in Effects of Factors influencing Negotiation Process

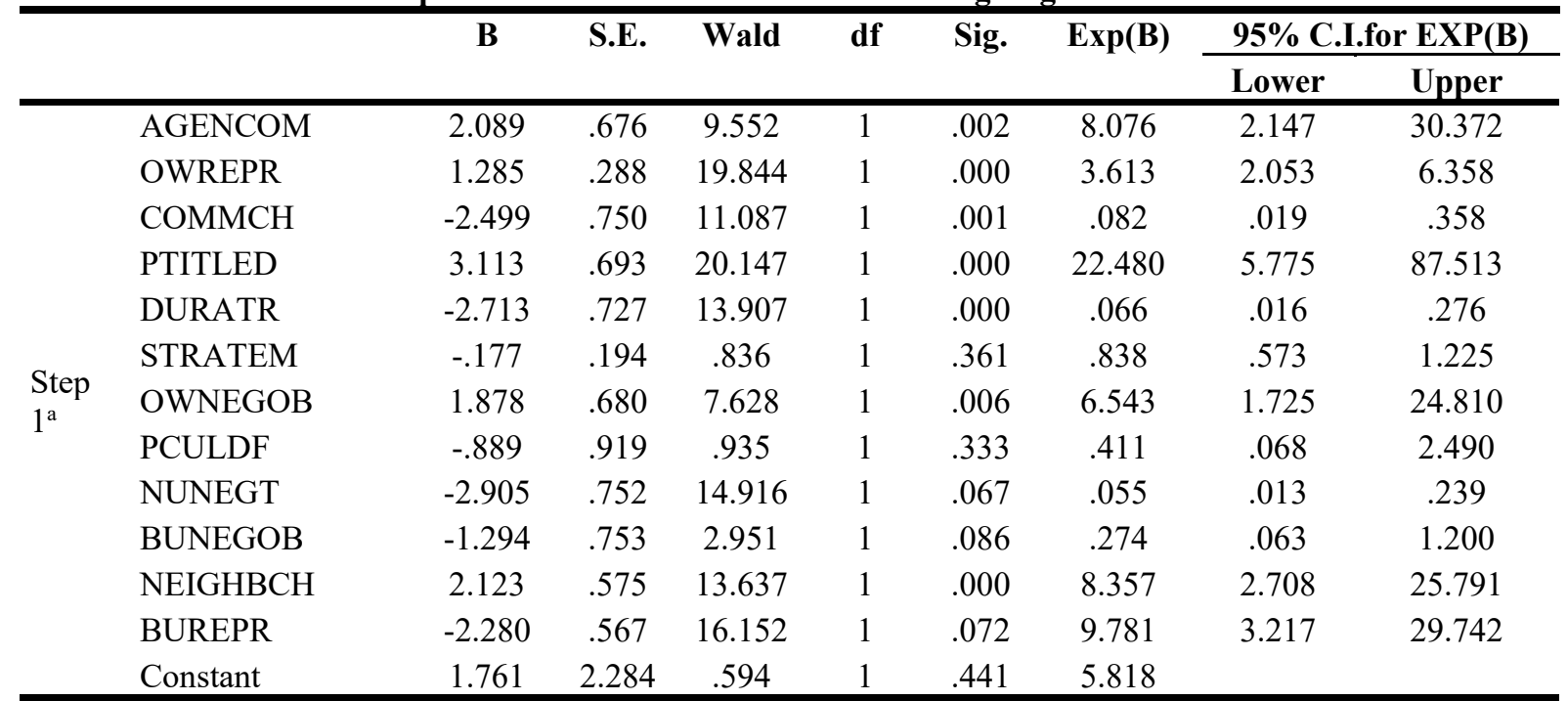

a. Variable(s) entered on step 1: Agencom, Owrerpr, Commch, PTitled, Duratr, Stratem, Ownegob, Culdf, Nunego, Bunegob, neighbch Burepr.

Thus, the significant variables in the model were agent commission, owners reservation price, communication channel, property titled, duration of transaction, owner negotiators behaviour and neighbourhood characteristics. The insignificant variables were strategy employed, cultural differences, number of negotiators, buyers behaviour and buyers reservation prices

Also, the B values showed the direction of the relationship (positive or negative). Negative B values indicated that an increase in the independent variable score would result in a decrease probability of the case recording a score of 1 in the dependent variable (Negotiation outcome). Thus, communication channel, duration of transaction, strategy employed, owners' negotiator behaviour, cultural differences, number of negotiators and buyers' negotiators behaviour showed negative B values $(-2.499,-2.713,-0.177,-0.889,-2.905$, and -1.294$)$ respectively. The positive B values indicated the key variables of influence on negotiation outcomes observed in the selected areas. Agents commission had a positive significant relationship. The factor was 2.089 showing that there is a (two) time possibility of belonging to the party that will pay the commission irrespective of its effect on negotiation outcome.

The variables in the equation output also included the $\operatorname{Exp}(\mathrm{B})$. known as the odds ratio predicted by the model. $\operatorname{Exp}(\mathrm{B})$ - is the exponentiation of the $\mathrm{B}$ coefficient, which is an odds ratio. This value is given by default because odds ratios can be easier to interpret than the coefficient, which is in log-odds units. In the model, for instance, the agents commission $\mathrm{e}^{2.089}=30.372$. , signifies that the odds of deciding to continue the analysis are 30.372 times higher than others for influencing the negotiation outcome.

The model for the effect of factors influencing negotiation outcome is as shown below:

Negotiation Outcome $(y)=1.761+2.089_{\text {Agents }}$ Commission +1.285 Owner Reservation Price

-2.499 Communication Channel +3.113 Property Titled -2.713 Duration of the Transaction $-0.177_{\text {Strategy Employed }}+1.878$ Owner Negotiator Behaviour -0.889 Party Cultural Difference -2.905 Number of Negotiators in Transaction -1.294 Buyer Negotiator Behaviour +2.123 Neighbourhood Characteristics -2.280 Buyer Reservation Price .................(2)

The findings of this study are in agreement with the studies of Thompson (2005, 2007), Iroham et.al (2011a), amongst other which noted that several factors such as agent commission, attitude toward time, strategy used, reservation prices from both parties, negotiators' behaviours and communication channel influence the fairness or otherwise of the negotiation outcome

Market negotiation ought to bring mutually beneficial outcome where both parties have equal information processing capability. In this study there was information assymetrry occasioned by buyers whose market information on previous transaction is absent and does not have reservation price to contend with the asking price of the owners' negotiators skill

Agents equally believed that the reservation price of the property owners as their clients often is their asking price which is mostly inconsistent with prevous market information, thereby leading to unfair/inefficient/ suboptimal outcome from buyers' viewpoints. Buyers' negotiation behaviour and reservation price even when required lower prices is mostly nil so the deal are mostly owners driven and super-optimal due to owners' information advantage over the second party-buyer. Since most transaction do not have independent buyers negotiators, the basis of analysing market information to determine market range and negotiate a fair outcome within that range in most transaction is conscupiously absent, hence unfair deal. This result is consistent with the 
result in Black,(1997) which stated that erroneous pricing information is often set by property owner and his agents; and with lack of knowledge of buyers to have adequate adjustment/ negotiation, the problem solving process may yield erroneous solutions/ bias and unfair outcome.

The duration of transaction too has not allowed fair outcome. Owners and his agents always desire quick sale, presenting the deal as one with many competitors which makes buyer to have been reaching agreement with them (for fear that they might lose the offer and there are no choice) even when the asking price is too high. This result is similar to -Fatima, Wooldridge and Jennings, 2004

Equally a negative communication channel to fair outcome shows that parties do not share enough information especially pricing information and so very consistent with McGinn and Keros 2003 that parties who share enough information are more likely to negotiate better that parties who either do not share or does differently.

\subsection{CONCLUSION AND RECOMMENDATION}

The study build on the established factors that could mostly influenced negotiation process of residential properties within a medium sized Akure city in Nigeria towards the final price of transaction known as market outcome. The dependent variable was the market outcome whether it was fair outcome or not. There were twelve independent variables namely; number of negotiators, whether it was seller or both parties negotiators; Agents commission from seller/buyer or both and the actual percentage; sellers' reservation prices whether it was higher than market range or not; buyers' reservation price whether its same as asking price or lower than it; communication channels between the parties whether its face to face or otherwise; strategy employed whether it was listening and sharing information or otherwise, sellers negotiation behaviour whether it was increase in market range or not. buyers' negotiations behaviours, no decrease in asking price or not; parties cultural differences whether parties were from same culture or not, duration of transactions in actual month/year; property titled or not; and neighbourhood characteristics whether in a serene environment or not. Thus, communication channels, duration of transaction, strategy employed, owners' negotiator behaviour, cultural differences, number of negotiators and buyers' negotiators behaviour showed negative beta values signified decreasing effects on the market outcome. The positive Beta values variables of influence on negotiation outcomes were agents commission, seller reservation price; titled property, sellers' negotiation behaviours and neighbourhood characteristics indicated increasing effects on the market outcome. Those variables of positive/increasing and negative/decreasing effects seem to show unfair outcome from the buyers' viewpoints. Yet, there were no cases of no deal/transactions despite high asking price that characterised most transactions. It was clear that previous years market sale to determine market range upon which the final outcome could have been based might not be considered. This suggests market bias, erroneous pricing and outcome that are economically imbalance and mutually un-beneficial.

The study therefore recommends detailed knowledge and understanding of the previous years market price, and present market range for buyers to strike a fair deal. This can be achieved through an independent skilled negotiator to achieve beneficial outcome Equally, the monopolistic advantage of the property owners and their agent must be broken by a parallel bodies that must be keeping the records of past landed properties sale / letting transactions and publicly displaying such information for the general public by market price regulatory agencies through a sensitisation /enlightenment campaign against undue influence in the market.

\section{References}

Amidu, A., and Aluko, B. T. (2007). Client influence in residential property valuations: An empirical study.Property Management, 25(5), 447-461.

Anderson, J.C. And Narus, J.A. (2004): Business Market Management. Upper Saddle River.

Bazerman, M. H., Curhan, J. R., More, D. A., \& Valley, K. J. (2000).Negotiation. Annual Review Of Psychology, $51,279-314$.

Black R. \& Diaz, J. (1996), The Use of Information Versus Asking Price in The Real Property Negotiation Process. Journal of Property Research Vol. 13, 43-45.

Black R. T. (1997) Expert Property Negotiators and Pricing Information, Revisited, Journal Of Property Valuation And Investment, 15(3).274- 281

Dirk, C.M., Alain, Y.C., Martins, J. L. and Bjoern, S. (2013). ANeural Network Approach to Predicting Price Negotiation Outcomes in Business to Business Context: Expert System with Applications-An International Journal, 40, 3028-3035

Fatima, S. Wooldridge, M. And Jennings, N. (2001). Optimal Negotiation Strategies For Agents With Incomplete Informationl, In, 8th International Workshop On Agent Theories, Architectures And Languages (Atal), Seattle, Usa.

Fatima, S. Wooldridge, M. And Jennings, N. (2004). An Agenda-Based Framework for Multi-Issue Negotiation, Artificial Intelligence, 152, 1-4.

Gatzlaffd. and Liu P. (2013).List Price Information in the Negotiation of Commercial Real Estate Transactions:: Is Silence Golden? Journal of Real Estate Finance.and Economics 47(4), 760-786 
Iroham, C. O., Oluwunmi, A. O. and Oluwatobi. A. O. (2011a) An Exposition On Principals’ Influence In Real Estate Negotiation.International Journal Of Marketing Studies.3 (2).169-175

Leigh, L. and Khakhar, P. (2015), The Effect Of Negotiator Characteristics On The Success Of International B2b Negotiations. Proceedings International Marketing Trends Conference, 2015.

Mcginn, K. L. and Keros. A. T. (2003). Improvisation And The Logic Of Exchange In Socially Embedded TransActions. Administrative Science Quarterly 47.

Muhlebach, R. (2005). The Seven Deadly Provisions. Journal Of Property Management, 70(3),. 44-6.

Neil, K \& Kevin, M. (1995), "Interest Based Negotiations" Retrieved from https://www.maxwell.syr.edu.parcc.cmc

Northcraft, G. And Neale, M. (1987), Experts, Amateurs, And Real Estate: An Anchoring-And- Adjustment Perspective On Property Pricing Decisions.|l Organizational Behavior And Human Decision Processes, 39(1).1.24

Rubin, J. Z., Pruitt, D. G. and Kim. S. H. (1994). Social Conflict: Escalation. Stalemate And Settlement, Boston: Mcgraw-Hill.

Sabine, Markus And Uta (2009), Information Asymmetry In Buyer-Seller Negotiations And Its Impact On Effectiveness, Efficiency And Satisfaction, Competitive Paper Main Session, 4-7.

Swaidan, Z. (2007). Culture and Negotiation Ethics. Review uf Business Research, 7(5), 17-36

Thompson, L. (1990). Negotiation behavior and outcomes: empirical evidence and theoretical issues.Psychological Bulletin, 108, 515-518.

Thompson, L. L. 2005. The Mind and Heart Of The Negotiator (3rd Ed.).Upper Saddle River, Nj: Pearson/Prentice Hall.

Zetik, D.C. and Stuhlmacher, A.F. (2002). Goal Setting and Negotiation Performance: A Meta- Analysis, Group Process \& Intergroup Relation., 35-52.

Willhermsson, M. (2008). Evidence of Buyers' Bargaining Power in the Stuckholm Residential Real Estate Market . Journal of Real Estate Research, 30, 233-244

Acknowledgements

I wish to acknowledge the efforts of my research assistant: Mr Egunleti Olaolo in the collection and collation of data used for the analysis. 